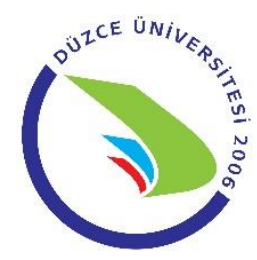

\title{
Primer Diz Osteoartritinde Total Diz Artroplastisi ve Konservatif Tedavi Sonrası Ağrı, Fiziksel Aktivite Düzeyi ve Fonksiyonellik
}

\author{
İlker ÇOLAK 國, Zehra Betül KARAKOÇ (i⿹ $^{2}$, Emel METE 國, Tuğçe ÖZEN 國, \\ Güven BULUT 國, Tuğba KURU ÇOLAK ${ }^{2}{ }^{2}$
}

Öz

Amaç: Diz eklemi osteoartritin en sık tuttuğu eklemdir ve diz osteoartriti ile ilişkili ağrı, günlük yaşam aktivitelerini kısıtlayarak fonksiyonel yetersizliğe yol açar. Bu araştırmanın amacı, primer diz osteoartriti nedeniyle total diz artroplastisi ve konservatif tedavi uygulanan hastaların tedavi sonrası ağrı, fiziksel aktivite ve fonksiyonellik düzeylerinin karşılaştırılmasıdır.

Gereç ve Yöntemler: Çalışmaya diz osteoartriti tanısı ile total diz artroplastisi uygulanan 30, konservatif tedavi olarak fizyoterapi uygulanan 30 ve 36 sağlıklı kontrol olmak üzere toplam 96 olgu dahil edildi. Ağrı düzeyi Vizuel Analog Skala ile, fiziksel aktivite Uluslararası Fiziksel Aktivite Anketi kısa form ile, semptom ve fonksiyonel durum Western Ontario ve McMaster Üniversiteleri Osteoartrit İndeksi ve Oxford Diz Skoru ile değerlendirildi. Değerlendirmeler cerrahi ve konservatif tedavi sonrası 3 - 6 ay arasında olmak üzere bir kez gerçekleştirildi.

Bulgular: Sonuçlar konservatif ve cerrahi tedavi uygulanan hastaların sağllklı kontrollere göre vücut kitle indekslerinin daha yüksek olduğunu $(p=0,001)$, fiziksel aktivite düzeylerinin daha düşük olduğunu $(p<0,001)$ göstermiştir. Konservatif tedavi uygulanan hastaların ağrı düzeylerinin daha düşük olduğu ancak total diz artroplastisi uygulanan hastaların fonksiyonel seviyelerinin daha iyi olduğu belirlenmiştir.

Sonuç: Tedavi sonrasında cerrahi tedavi uygulanan hastaların ağrı düzeylerinin daha düşük olduğu ve fonksiyonel seviyelerinin daha iyi olduğu belirlenmiştir. Kilo kontrolünün sağlanması ile diz osteoartritine bağlı semptomlar azaltılabilir ve cerrahi tedavi geciktirilebilir. Cerrahi sonrası dönemde hastaların ağrı düzeylerinin azaltılması ve fiziksel aktivite düzeylerinin geliştirilmesi için hastalar ortopedik rehabilitasyon programlarına yönlendirilmelidir.

Anahtar Kelimeler: Diz; osteoartrit; total diz replasman1; rehabilitasyon.

\section{Pain, Physical Activity Level and Functionality in Primary Knee Osteoarthritis after Total Knee Arthroplasty and Conservative Treatment}

\begin{abstract}
Aim: The knee joint is the most commonly involved joint in osteoarthritis, and pain associated with knee osteoarthritis leads to functional impairment by limiting daily living activities. The aim of this study was to compare pain, physical activity and functionality levels of patients applied with surgical or conservative treatment for primary knee osteoarthritis.

Material and Methods: Total knee arthroplasty was applied to 30 patients, conservative physiotherapy treatment to 30 patients and a control group was formed of 36 age-matched healthy individuals. Pain was assessed with a Visual Analogue Scale, physical activity with the International Physical Activity Questionnaire short form, symptoms and functional status with the Western Ontario and McMaster University Osteoarthritis Index and the Oxford Knee Score. Assessments were made once at 3-6 months after surgical and conservative treatment.

Results: The results showed that body mass index was higher $(\mathrm{p}=0.001)$ and physical activity levels were lower $(\mathrm{p}<0.001)$ in patients who underwent conservative and surgical treatment compared to the healthy control group. Pain levels were lower and functional levels were better in patients who had undergone total knee arthroplasty.

Conclusion: Pain levels were lower and functional levels were better in patients who received surgical treatment. Weight control can relieve symptoms related to knee osteoarthritis and help to avoid surgical treatment. Patients should
\end{abstract}

1 Kartal Dr. Lütfi Kırdar Eğitim ve Araştırma Hastanesi, Ortopedi ve Travmatoloji Kliniği, İstanbul, Türkiye

2 Marmara Üniversitesi, Sağlık Bilimleri Fakültesi, Fizyoterapi ve Rehabilitasyon Bölümü, İstanbul, Türkiye 
be referred to orthopedic rehabilitation programs to reduce pain and improve physical activity levels in the postoperative period.

Keywords: Knee; osteoarthritis; total knee replacement; rehabilitation.

\section{Gíiș}

Osteoartrit (OA) erişkinlerde görülen eklem hastalıklarından en yaygın olanıdır (1). Diz osteoartriti erişkinlerin \%6'sında görülür ve diz eklemi osteoartritin en sık tuttuğu eklemdir (2); diz osteoartriti ile ilişkili ağrı, günlük yaşam aktivitelerini kısıtlayarak fonksiyonel yetersizliğe yol açar (3-5).

Pirmer OA yavaş ve progresif olarak diz ekleminin 1 ya da 3 major kompanentini etkiler. Yapısal ve mekanik faktörler diz OA geşiminde rol oynar. Osteoartrit, eklem kıkırdağının proteoglikan içeriğinde azalma ile su içeriğindeki bir artışla doğrudan ilişkilidir. Kollajen seviyeleri arttıkça, mevcut kollajen ciddi şekilde bozulur. Yüksek seviyelerde proteolitik enzimler ve enflamatuar sitokinlerle, bu kısır döngü devam eder; eklem daha artritik ve ağrılı hale gelir (6).

Diz OA olan hastalar için güncel tedavi yöntemleri biyomekanik girişimler, eklem içi enjeksiyonlar, egzersiz yöntemleri, elektroterapi yöntemleri, hasta eğitimi, kilo kontrolü, yürüme yardımcıları ve ortezler, medikal tedavi ve son olarak cerrahi yaklaşım olarak sayılabilir (2,7-10). Ortopedik cerrahlar 1970'li yıllarda total diz artroplastisi yapmaya başlamışlardır. Günümüzde, hastaların çoğunluğu için yararlı olan ve yaşam kalitesini geliştiren, uygun maliyetli, yaygın olarak uygulanan bir cerrahi prosedürdür. Egzersiz ve diğer fizyoterapi yöntemleri ise OA semptompları olan genç ve orta yaşlı hastalarda ya da cerrahi tedaviyi geciktirmek isteyen hastalar için endikedir (11).

Konservatif tedavi uygulamaları ile yapısal değişiklikler geri döndürülemese de ağrı ve fonksiyonel kısıtlılık gibi belirgin semptomlar azalt1labilir (10-12). Konservatif tedavilerden yanit alınamayan durumlarda, hastanın semptomları fiziksel ve radyolojik bulgular ile uyumlu olduğunda artroskopik diz cerrahilerine ya da total diz artroplastisine başvurulmaktadır $(8,13)$. Total diz cerrahilerinin de ağrı, fonksiyonellik ve yaşam kalitesine olan olumlu etkileri bildirilmiştir $(11,13)$. $\mathrm{Bu}$ araştırmanın amacı, primer diz osteoartriti olan hastaların cerrahi ve konservatif tedavi sonrası kısa dönemde ağrı, fonksiyonellik ve fiziksel aktivite düzeylerinin karşılaştırılması ve sonuç ölçümlerinin sağlıklı kontrollerle kıyaslanmasidır.

\section{GEREÇ VE YÖNTEMLER}

Tanımlayıcı, kesitsel bir çalışma olan araştırmamız, Nisan 2016 ve Kasım 2018 tarihleri arasında Kartal Dr. Lütfi Kırdar Eğitim ve Araştırma Hastanesi Ortopedi ve Travmatoloji Kliniği'nde primer diz osteoartrit tanısı almış olan ve çalışmaya katılmayı kabul eden gönüllü olgular üzerinde gerçekleştirildi. Çalışmaya dahil edilme kriterleri; en az bir sene önce osteoartrit tanısı almış olmak, Amerika Romatoloji Birliği kriterlerine göre primer osteoartrit tanısı almış olmak, son 6 ay içinde herhangi bir ortopedik travma geçirmemiş olmak, konservatif tedavi öncesinde cerrahi geçirmemiş olmaktı. Çalışmaya alınmama kriterleri ise çalışmadan önce son 3 ay içinde herhangi bir konservatif tedavi almış olmak, son 12 ay içinde alt ekstremite fraktürü geçirmiş olmak, ek ortopedik ve romatolojik hastalıklar, kontrol edilemeyen komorbid hastalıklar, demans veya konuşma problemine sahip olmak, nörolojik bir rahatsızlığı bulunmaktı.

Dahil edilme kriterlerini taşıyan, diz osteoartriti tanısı ile total diz artroplastisi uygulanan 30, konservatif tedavi uygulanan 30 ve 36 sağlıklı kontrol olmak üzere toplam 96 olgu çalışmaya dahil edildi. Çalışmaya dahil edilen olgulardan sözlü ve yazılı onamları istendi. Çalışma Marmara Üniversitesi Sağlık Bilimleri Enstitüsü Etik Kurulu tarafindan 22.02.2016 - 11 onay tarihi ve sayıs ile onaylandı ve Helsinki Bildirgesi'ne uygun olarak yürütüldü.

Konservatif tedavi uygulanan hastalara 3 hafta boyunca toplam 15 seans, diz eklemi üzerine hot pack (15 dk), diz eklemi çevresine, özellikle ağrılı bölgeyi içine alacak şekilde 2 kanal, 4 elektrot ile konvansiyonel TENS (Transcutaneous electrical nerve stimulation, Chattanooga Intelect, USA, $100 \mathrm{~Hz}, 60 \mu \mathrm{s})$ ve $5 \mathrm{dk}$ terapotik ultrason (Chattanooga Intelect, USA, $1 \mathrm{MHz}, 1$ watt/cm2) ve alt ekstremite için genel kuvvetlendirme ve germe egzersizleri (Hamstring ve kalf kaslarına germe, izometrik quadriceps, düz bacak kaldırma ve yatakta topuk kaydırma egzersizleri, 10 sn germe ve kontraksiyon ile 10'ar tekrarli) uyguland1. Diz OA'i Kellegren Lawrence (13) (sınıflamasina göre evre 3-4 olan ve uzman hekim tarafindan cerrahi endikasyon belirlenen hastalara 2 ortopedist tarafindan median parapetallar insizyon ile arka çapraz bağ korunarak total diz artroplastisi uyguland. Cerrahi tedavi uygulanan hastalar post-operatif 3. gün taburcu edildiler ve bu sürede fizyoterapist tarafindan hastanede günde $2 \mathrm{kez}$ rehabilitasyon programı (ayak bileği pompalama, gluteal ve quadriceps kaslarına izometrik egzersizler, yatakta diz fleksiyonu, oturmadan ayağa kalkma) uygulandı. Hastalar taburculuk sonrası fizyoterapi programı almadılar. Konservatif tedavi programı içinde yer alan elektroterapi ve egzersiz programları ile cerrahi tedavi sonrası uygulanan fizyoterapi programı üç fizyoterapist tarafindan uygulandi.

Tüm olguların ağrı düzeyleri Vizuel Ağrı Skalası (VAS) ile, fiziksel aktiviteleri Uluslararası Fiziksel Aktivite Anketi Kisa Formu (UFAA-KF) ile, semptom ve fonksiyonel durumlarını Western Ontario ve McMaster Üniversiteleri Osteoartrit İndeksi (WOMAC) ile Oxford Diz Skoru ile değerlendirildi. Değerlendirmeler konservatif ve cerrahi tedavi sonrası $3-6$ ay arasında olmak üzere bir kez gerçekleştirildi.

Vizuel Analog Skalası (VAS), $100 \mathrm{~mm}$ uzunluğunda bir çizgi olan bu skalanın sol kısmı en düşük, sağ tarafı da yüksek ağrı şiddetini tanımlamak için kullanılır. Olgulardan bu çizgi üzerinden ağrı şiddetlerine göre işaretleme yapmaları istendi (16).

Uluslararası Fiziksel Aktivite Anketi (UFAA) kısa form, subjektif olarak fiziksel aktivitenin frekansı, şiddeti ve süresi hakkında bilgi vermektedir. Olgulardan referans noktası olarak son bir haftayı veya rutin bir haftay1 almaları istenmektedir. Olguların bildirimlerine göre haftalık dakika cinsinden metabolik eşdeğerlilikleri (MET) hesaplanarak fiziksel aktivite düzeyleri düşük, orta ve yüksek olarak sınıflandırılmaktadır. Geçerli ve 
güvenilir bir anket olarak birçok dilde ve dilimizde kullanılmaktadır $(17,18)$.

Oxford Diz Skoru, dize bağlı yaşam kalitesi ve uygulanan tedavinin etkinliği konusunda bilgi almak için kullanılan geçerli ve güvenilir bir ölçektir. 12 maddeden oluşur ve her soru en iyiden ciddi disabiliteye doğru 1-5 puan arasında puanlandırılır $(19,20)$.

Western Ontario ve McMaster Üniversiteleri Osteoartrit İndeksi (WOMAC) skalası, olgulara yönelik osteoartrit semptomları ve fonksiyonel disabiliteyi sorgulayan sorulardan oluşur. Ağrı (5 soru), fonksiyonel disabilite (17 soru) ve sertliği (2 soru) ölçen toplam 24 sorudan oluşmaktadır. Her soru Likert sistemine göre puanlanır. Bölümlerin ortalama değerleri alınarak toplam skor belirlenir. Daha önce yapılan araştırmalarda skalanın geçerliliği ve güvenilirliği gösterilmiştir $(19,21,22)$.

\section{İstatistiksel Analiz}

Çalışmanın örneklem büyüğü hesaplaması için G*Power V3.1.9.2 kullanılmıştır. Bağımsız çoklu grup ortalamaları yaklaşımıyla literatürdeki yapılan çalışmalar üzerinden hesaplanan etki büyüklüğü (Grup1=46,4 $\pm 4,3$, Grup2 $=45,5 \pm 3,6$ ve Grup3 $=45,8 \pm 4,0) \quad \mathrm{f}=0,374$ olarak hesaplanmıştır. Buna göre $\alpha=0,051$. tip hata olasılığ 1 için 0,80 güçte, 3 grupta toplam ulaşılması gereken minimum örneklem büyüklüğü 72 (gruplarda minimum 24 kişi olmak üzere) kişi olarak hesaplanmıştır.

Elde edilen ölçümler SPSS 16.0 istatistik programı ile $\% 95$ 'lik güven aralığında, anlamlılık $\mathrm{p}<0,05$ düzeyinde değerlendirildi. Normallik varsayımı Kolmogorov Smirnov testi ile analiz edildi. Normal dağılıma uyan değişkenlerin gruplar arası karşılaştırması tek yönlü varyans analizi (ANOVA) ile gerçekleştirildi. Grupların birbirlerine üstünlüğünün belirlenmesi için Post-Hoc testlerden Bonferroni düzeltmesi uygulandi. Normal dağılıma uymayan değişkenler Kruskal Wallis testi ile analiz edildi. Grupların ikili karşılaştırması ise Bonferroni düzeltmeli Mann Whitney U testi ile gerçekleştirildi. Kategorik değişkenlerin gruplar arası kıyaslaması ise Chi-square testiyle gerçekleştirildi.

\section{BULGULAR}

Üç grubun klinik ve demografik özellikleri kıyaslandığında, grupların ortalama kilo değerleri arasında anlamlı farklılık olduğu belirlendi (Tablo 1).Gruplar ikili olarak kıyaslandığında ise sağlıklı kontrol grubunun ortalama kilo değeri ile cerrahi uygulanan grubun kilo değeri arasında istatistiksel olarak anlamlı farklılık mevcuttu $(\mathrm{p}=0,014)$. Sağlıklı kontrol grubunun VKI ortalama değerleri istatistiksel olarak anlamlı düzeyde diğer iki gruptan daha düşüktü $(p=0,001)$; konservatif tedavi grubunun da VKI değerleri cerrahi tedavi uygulanan gruptan daha düşüktü $(p=0,025)$. Konservatif tedavi uygulanan grupta anlamlı düzeyde daha fazla bilateral ekstremite etkilenimi söz konusuydu. Konservatif ve cerrahi tedavi gören hastaların tümünün dominant ekstremitesi sağ taraf idi.

İstirahat ve aktivite ağrı skorları konservatif tedavi gören grupta anlamlı düzeyde daha yüksekti (Tablo 2) $(p<0,001)$. Sağlıklı kontrol grubu en yüksek fiziksel aktivite düzeyine, cerrahi tedavi uygulanan grup da en düşük fiziksel aktivite düzeyine sahipti. Konservatif ve cerrahi tedavi uygulanan hastaların toplam UFAA-KF skorları istatistiksel olarak benzerdi. Sağlıklı kontrol grubu ile konservatif tedavi uygulanan hastaların haftalık oturma süreleri benzerdi, cerrahi tedavi uygulanan grup en yüksek oturma süresine sahipti. Konservatif ve cerrahi tedavi uygulanan gruplarda Oxford diz skorları benzer iken; WOMAC skorları $(\mathrm{p}=0,009)$ arasında istatistiksel olarak anlamlı farklılı mevcuttu.

Tablo 1. Grupların klinik ve demografik özellikleri

\begin{tabular}{|c|c|c|c|c|}
\hline 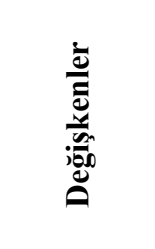 & $\begin{array}{c}\text { Sağlıkı Kontrol Grubu } \\
\text { Ort } \pm \text { SD } \\
\text { Medyan (min-maks) } \\
\text { Frekans (\%) } \\
(\mathbf{n}=\mathbf{3 6})\end{array}$ & $\begin{array}{c}\text { Cerrahi Tedavi Grubu } \\
\text { Ort } \pm \text { SD } \\
\text { Medyan (min-maks) } \\
\text { Frekans }(\%) \\
(\mathbf{n}=30)\end{array}$ & $\begin{array}{c}\text { Konservatif Tedavi } \\
\text { Grubu } \\
\text { Ort } \pm \text { SD } \\
\text { Medyan (min-maks) } \\
\text { Frekans }(\%) \\
(\mathbf{n}=30)\end{array}$ & p değeri \\
\hline Yaş (yıl) & $\begin{array}{c}62,8 \pm 8,1 \\
62(50,0-91,0)\end{array}$ & $\begin{array}{c}64,9 \pm 7,7 \\
65(45-79)\end{array}$ & $\begin{array}{c}64,1 \pm 7,32 \\
64(55-80)\end{array}$ & 0,357 \\
\hline Boy (cm) & $\begin{array}{c}164,3 \pm 8,5 \\
165(148-180)\end{array}$ & $\begin{array}{c}162,1 \pm 7,7 \\
160(150-182)\end{array}$ & $\begin{array}{c}163,7 \pm 7,2 \\
162,5(152-180)\end{array}$ & 0,380 \\
\hline Kilo (kg) & $\begin{array}{l}76,4 \pm 13,1 \\
(45-105)\end{array}$ & $\begin{array}{l}85,4 \pm 11,3 \\
(65-120)\end{array}$ & $\begin{array}{l}78,9 \pm 12,7 \\
(50-110)\end{array}$ & 0,015 \\
\hline VKI & $\begin{array}{c}28,4 \pm 4,5 \\
(18,7-38,5)\end{array}$ & $\begin{array}{c}32,7 \pm 5,1 \\
(25,3-48,1)\end{array}$ & $\begin{array}{c}29,4 \pm 4,5 \\
(20,5-38,7)\end{array}$ & 0,001 \\
\hline Cinsiyet & $\begin{array}{l}\text { Kadın } 25(\% 75) \\
\text { Erkek } 11(\% 25)\end{array}$ & $\begin{array}{l}\text { Kadın } 25(\% 76) \\
\text { Erkek } 5(\% 24)\end{array}$ & $\begin{array}{l}\text { Kadın } 24(\% 80) \\
\text { Erkek } 6(\% 20)\end{array}$ & 0,368 \\
\hline $\begin{array}{l}\text { Etkilenen } \\
\text { taraf }\end{array}$ & - & $\begin{array}{c}15 \text { sağ } \\
14 \text { sol } \\
1 \text { bilateral }\end{array}$ & $\begin{array}{c}8 \mathrm{sağ} \\
7 \mathrm{sol} \\
15 \text { bilateral }\end{array}$ & $<0,001$ \\
\hline
\end{tabular}

Ort: ortalama, SD: Standart sapma, min: minimum, maks: maksimum, VKI: vücut kitle indeksi 
Tablo 2. Grupların değerlendirme sonuçlarının karşılaştırılması

\begin{tabular}{|c|c|c|c|c|}
\hline 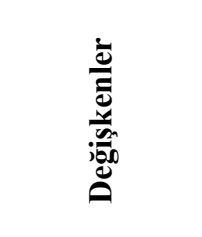 & $\begin{array}{c}\text { Sağlıklı Kontrol Grubu } \\
\text { Ort } \pm \text { SD } \\
\text { Medyan (min-maks) } \\
\text { Frekans }(\%) \\
(n=36)\end{array}$ & $\begin{array}{l}\text { Cerrahi Tedavi Grubu } \\
\text { Ort } \pm \text { SD Medyan (min- } \\
\text { maks) } \\
\text { Frekans }(\%) \\
(\mathbf{n}=30)\end{array}$ & $\begin{array}{c}\text { Konservatif Tedavi } \\
\text { Grubu } \\
\text { Ort } \pm \text { SD } \\
\text { Medyan (min-maks) } \\
\text { Frekans }(\%) \\
(\mathbf{n}=\mathbf{3 0})\end{array}$ & $\begin{array}{c}\text { p değeri } \\
\text { G1-G2-G3 } \\
\text { G1-G2 } \\
\text { G1-G3 } \\
\text { G2-G3 }\end{array}$ \\
\hline $\begin{array}{c}\text { VAS } \\
\text { istirahat }\end{array}$ & - & $\begin{array}{l}1,1 \pm 1,6 \\
0(0-7)\end{array}$ & $\begin{array}{l}3,6 \pm 2,5 \\
4(0-8)\end{array}$ & $<0,001$ \\
\hline VAS aktivite & - & $\begin{array}{l}3,3 \pm 2,6 \\
3(0-9)\end{array}$ & $\begin{array}{c}6,7 \pm 2,1 \\
7(2-10)\end{array}$ & $<0,001$ \\
\hline $\begin{array}{l}\text { Total UFAA- } \\
\text { KF skoru }\end{array}$ & $\begin{array}{c}3019,4 \pm 2318,3 \\
2226(396-9462)\end{array}$ & $\begin{array}{c}483,5 \pm 309,8 \\
424(0-1386)\end{array}$ & $\begin{array}{c}1095,1 \pm 1259,3 \\
726(0-5790)\end{array}$ & $\begin{array}{c}<\mathbf{0 , 0 0 1} \\
<\mathbf{0 , 0 0 1} \\
<\mathbf{0 , 0 0 1} \\
0,075\end{array}$ \\
\hline $\begin{array}{l}\text { UFAA-KF } \\
\text { fiziksel } \\
\text { aktivite } \\
\text { düzeyi }\end{array}$ & $\begin{array}{c}\text { Yüksek düzey } 16(\% 44,4) \\
\text { Orta düzey } 19(\% 52,8) \\
\text { Düşük düzey } 1(\% 2,8)\end{array}$ & $\begin{array}{l}\text { Yüksek düzey } 1(\% 3,3) \\
\text { Orta düzey } 8(\% 26,7) \\
\text { Düşük düzey } 21(\% 70)\end{array}$ & $\begin{array}{c}\text { Yüksek düzey } 2(\% 6,7) \\
\text { Orta düzey } 15(\% 50) \\
\text { Düşük düzey } 13(\% 43,3)\end{array}$ & $\begin{array}{c}<\mathbf{0 , 0 0 1} \\
<\mathbf{0 , 0 0 1} \\
<\mathbf{0 , 0 0 1} \\
0,043\end{array}$ \\
\hline $\begin{array}{l}\text { UFAA-KF } \\
\text { oturma } \\
\text { süresi } \\
\text { (dk/gün) }\end{array}$ & $\begin{array}{c}530 \pm 172 \\
540(270-900)\end{array}$ & $\begin{array}{c}768,5 \pm 200,8 \\
720(450-1350)\end{array}$ & $\begin{array}{c}542,7 \pm 251,3 \\
540(135-900)\end{array}$ & $\begin{array}{c}<\mathbf{0 , 0 0 1} \\
<\mathbf{0 , 0 0 1} \\
0,984 \\
\mathbf{0 , 0 0 1}\end{array}$ \\
\hline $\begin{array}{l}\text { Oxford Diz } \\
\text { skoru }\end{array}$ & $\begin{array}{c}44,5 \pm 3,2 \\
45(36-48)\end{array}$ & $\begin{array}{c}27,4 \pm 11,3 \\
28,5(5-47)\end{array}$ & $\begin{array}{c}24,1 \pm 8,4 \\
23(8-40)\end{array}$ & $\begin{array}{c}<\mathbf{0 , 0 0 1} \\
<\mathbf{0 , 0 0 1} \\
<\mathbf{0 , 0 0 1} \\
0,190\end{array}$ \\
\hline $\begin{array}{l}\text { WOMAC } \\
\text { Toplam } \\
\text { skoru }\end{array}$ & $\begin{array}{c}4,3 \pm 3,1 \\
6,5(0-11)\end{array}$ & $\begin{array}{l}29,2 \pm 16,7 \\
27(3-68)\end{array}$ & $\begin{array}{c}42,8 \pm 20,2 \\
42,5(9-84)\end{array}$ & $\begin{array}{c}<0,001 \\
<0,001 \\
<0,001 \\
\mathbf{0 , 0 0 9}\end{array}$ \\
\hline
\end{tabular}

Ort: ortalama, SD: Standart sapma, min: minimum, maks: maksimum, G1: Sağlıklı kontrol grubu, G2: Cerrahi tedavi grubu, G3: Konservatif tedavi grubu, VAS: vizuel analog skala, UFAA-KF: Uluslararası Fiziksel Aktivite Anketi k1sa form, WOMAC: Western Ontario ve McMaster Üniversiteleri Osteoartrit İndeksi

\section{TARTIŞMA}

Çalışmanın sonuçları konservatif ve cerrahi tedavi uygulanan primer diz osteoartriti olan hastaların sağlıklı kontrollere göre vücut kitle indekslerinin daha yüksek olduğunu, fiziksel aktivite düzeylerinin daha düşük olduğunu göstermiştir. Cerrahi tedavi uygulanan hastaların ağrı düzeylerinin daha düşük olduğu ve fonksiyonel seviyelerinin daha iyi olduğu belirlenmiştir.

Diz osteoartritinin obez kadınlarda 5 kat, obez erkeklerde ise 4 kat fazla görüldüğü literatürde bildirilmiştir $(23,24)$. Benzer şekilde bu çalışmada da primer diz osteoartriti nedeniyle konservatif ve cerrahi tedavi uygulanan gruplarda kilo ve VKI ortalama değerlerinin daha yüksek olduğu belirlenmiştir. Önemli bir bulgu da diz artroplastisi endikasyonu almış olan hastaların kilo ve VKI'lerinin daha yüksek olmasıdır. Bunun nedeni şiddetli diz osteoartritinin hastaların fiziksel aktivitelerini k1sıtlaması olabileceği gibi obezitenin diz osteoartriti şiddetini arttırması da olabilir. Obezitenin kıkırdak dejenerasyonu üzerindeki etkisi net olarak belirlenmemiş olmakla birlikte mekanik, humoral ve genetik faktörlerin etkili olduğu düşünülmektedir (25). Artan adiopoz dokunun humoral sistem değişikliklerine neden olduğu ve eklem kıkırdağı metabolizmasını değiştirdiği düşünülmektedir. Leptin sistemi ile obezitedeki metabolik anormallikler ve artmış OA riski arasında bir bağlantı olabileceği öne sürülmüştür (26). Sadeghi ve ark. (27) kilo kontrolü ile diz osteoartriti semptomlarının anlamlı düzeyde iyileştiğini göstermişlerdir. Bu sonuç diz osteoartriti semptomları olmayan sağlıklı kontrol grubunda vücut kitle indeksi değerlerinin daha düşük olması ile uyumludur.

Literatürde TENS ve farklı konvansiyonel fizyoterapi uygulamalarının diz osteoartritinde ağrıyı azalttığı, fonksiyonelliği geliştirdiği gösterilmiştir (28-30). Cerrahi tedavi uygulamasindan sonra diz osteoartritinde semptompların azalması beklenir.

Çalışmamızda konservatif ve cerrahi tedavi uygulandıktan sonra hastaların ağrı seviyeleri VAS ile değerlendirilmiştir. Cerrahi tedavi uygulanan hastaların ağrı seviyeleri anlamlı olarak daha düşük bulunmuştur. OA kemik, kartilaj ve sinovya olmak üzere tüm eklem yapılarını etkileyen bir hastalıktır. Güncel araştırmalar, olguların çoğunda subkondral kemiğin altında meydana 
gelen kemik iliği lezyonlarının, sinovitin, periferik ve santral ağrı duyarlılığındaki değişimlerin ağrı oluşumuna yol açtığını göstermektedir. Ayrıca, OA bulunan eklemlerde inflamatuar sitokinlerin (TNF- $\alpha$, IL-1, IL-6, IL-15, IL-10, kemokinler, MCP-1 ve fraktalkin) eklem nosiseptörlerini uyararak ağrı oluşumuna neden olduğu düşünülmektedir (31-32). Cerrahi tedavi ile ağrıya neden olan yapısal değişikliklerin ortadan kaldırılması ve alt ekstremite biyomekanik dizilimin sağlanması gibi faktörlerin cerrahi uygulanan grubun daha iyi ağr1 skorlarına sahip olmasının nedenleri olabileceğini düşünmekteyiz.

Bireylerin fiziksel aktivite düzeyleri UFAA-KF skoru ile değerlendirildi. Cerrahi tedavi uygulanan grubun en az fiziksel aktivite skoruna sahip olduğu, en yüksek oturma süresine sahip olduğu ve bu gruptaki hastaların \%70'inin düşük fiziksel aktivite düzeyine sahip olduğu belirlenmiştir. Sağlıklı kontrol grubu ise en yüksek fiziksel aktivite skoruna ve en az oturma süresine sahiptir. Yaşlanma ile artan inaktivite ve OA ile ilişkili ağrı ya da kas zayıflığ 1 ve obezite nedeniyle diz OA'li kişilerin egzersizden uzak durdukları ve sağlıklı kontrollere göre daha inaktif oldukları bildirilmiştir $(33,34)$. Güncel bir hayvan çalışmasında sedanter yaşamın diz osteoartriti gelişmesine neden olduğu ve hastalık şiddetini arttırdığ belirlenmiştir (35). Bu bulgu bizim çalışmamızın sonuçları ile paraleldir. Bir başka araştırma da ise erkeklerde şiddetli fiziksel aktivitenin diz OA ile ilişkili olduğunu kadınlarda bu etkinin görülmediğini öne sürülmüştür (36).

Önceki araştırmalarda total diz ve kalça artroplastisi uygulanan hastaların fiziksel aktivite düzeyinin geliştirilmesi için fizyoterapist süpervizyonu ile grup içinde ortopedik rehabilitasyon uygulamasının etkili olduğu bildirilmiştir (37-39). Hastalar cerrahi sonrası opere olan ekstremitelerini koruma eğiliminde oldukları için hareket etmekten de kaçınmaktadırlar. İmmobilizasyon ve sedanter yaşam cerrahi sonrası komplikasyonları da arttırabileceği için erken dönemde hastaların rehabilitasyon programlarına yönlendirilmesi önem taşımaktadır.

Hastaların fonksiyonel düzeyleri Oxford ve WOMAC skalaları ile değerlendirilmişitir. Her iki değerlendirme parametresinde de cerrahi uygulanan grubun konservatif tedavi uygulanan gruptan daha yüksek fonksiyonel düzeye sahip olduğu saptanmıştır. Diz ekleminde hareket kısıtlılığının azalması nedeniyle cerrahi tedavi uygulanan hastaların konservatif tedavi uygulanan hastalara göre daha iyi fonksiyonel sonuçlar rapor etmesi beklenen bir sonuç olabilir. Su ve arkadaşlarının 5 yıllık retrospektif araştırmasında artroskopik tedavi uygulanan diz osteoartriti hastalarında WOMAC skorlarının konservatif tedavi uygulananlara göre anlamlı düzeyde iyi olduğunu bildirmişlerdir (40). Bir başka randomize kontrollü çalışmada ise total diz artroplastisini takiben uygulanan 12 haftalık rehabilitasyon programının, tek başına uygulanan rehabilitasyon programına göre ağrı ve fonksiyonellik sonuçları bakımından üstünlük sağladığı belirtilmiştir (41). Gelecekte yapılacak çalışmalarda cerrahi tedavi uygulanan ve uygulamayan hastalarda farklı konservatif tedavi uygulamalarının sonuç ölçümlerine sağladığı üstünlüklerin araştırılmasını önermekteyiz.
Tedavi öncesi değerlendirmenin olmaması ve tedavi sonrası değerlendirmelerle karşılaştırılamaması, erkek cinsiyet az olduğu için cinsiyete göre kıyaslama yapılamaması, uzun süreli takip olmaması, konservatif tedavi uygulanan grupta hastaların çoğunun bilateral etkilenime sahip olması çalışmamızın limitasyonları olarak kabul edilebilir. Fiziksel aktivite ve fonksiyonellik ölçümleri subjektif olarak hastaların kendi bildirimlerine göre belirlenmiştir. Objektif ölçümler farklı sonuçların elde edilmesini sağlayabilir. Sağlıklı kontrol grubunun olması çalışmanın üstünlüğü olarak kabul edilebilir ancak sağlıklı kontrol grubunun semptomu olmadığ 1 için radyolojik değerlendirmeleri yapılmamıştır.

Klinik tecrübelerimiz kilo kontrolünün sağlanması ile diz osteoartritine bağlı semptompların azaldığını göstermektedir; bu şekilde cerrahiye gidiş süresi de ertelenebilir. VKI azaltılmasının yanı sıra diz osteoartriti tanısı alan hastalar iyi bir rehabilitasyon programı ile alt ekstremite için uygulanacak genel germe ve güçlendirme egzersizleri diz eklemine binen yüklerin azaltılmasında yararlı olabilir. Ancak ciddi fonksiyonel kısıtlılığı ve yaşam kalitesi etkilenimi olan hastalarda total diz artroplastisi uygulaması ile hastalarda çok iyi gelişme elde edilmektedir. Cerrahi sonrası dönemde daha iyi fonksiyonel sonuçlar elde edilmesi, ağrı kontrolünün sağlanması ve ağrı ile baş etme yollarının öğrenilmesi, fiziksel aktivite düzeyinin arttırılması için fizyoterapist süpervizörlüğünde ortopedik rehabilitasyon programları uygulanmalidir.

Yazarların Katkıları: Fikir/Kavram: İ.Ç., T.K.Ç.; Tasarım: İ.Ç., G.B., T.K.Ç.; Veri Toplama ve/veya İşleme: İ.Ç., Z.B.K., E.M., T.Ö., T.K.Ç.; Analiz ve/veya Yorum: İ.Ç., T.K.Ç.; Literatür Taraması: İ.Ç., Z.B.K., E.M., T.Ö., T.K.Ç.; Makale Yazımı: İ.Ç., T.K.Ç.; Eleştirel İnceleme: İ.Ç., G.B., T.K.Ç.

\section{KAYNAKLAR}

1. Felson DT. Epidemiology of knee and hip osteoarthritis. Epidemiol Rev. 1988; 10: 1-28.

2. Michael JW, Schlüter-Brust KU, Eysel P. The epidemiology, etiology, diagnosis, and treatment of osteoarthritis of the knee. Dtsch Arztebl Int. 2010; 107(9): 152-62.

3. Covinsky K. Aging, arthritis, and disability. Arthritis Rheum. 2006; 55(2): 175-6.

4. Dunlop DD, Manheim LM, Song J, Chang RW. Arthritis prevalence and activity limitations in older adults. Arthritis Rheum. 2001; 44(1): 212-21.

5. Cross M, Smith E, Hoy D, Nolte S, Nolte S, Ackerman I, Fransen M, et al. The global burden of hip and knee osteoarthritis: estimates from the global burden of disease 2010 study. Ann Rheum Dis. 2014; 73(7): 1323-30.

6. Martin JA, Ramakrishnan PA, Lim T, Thedens D, Buckwalter JA. Articular cartilage and intervertebral disk. In: Flynn JM, editor. Orthopaedic knowledge update. 10th ed. Rosemont, IL: American Academy of Orthopaedic Surgeons; 2011. p. 23-6.

7. Hochberg MC, Altman RD, April KT, Benkhalti M, Guyatt G, McGowan J, et al. American College of Rheumatology 2012 recommendations for the use of nonpharmacologic and pharmacologic therapies in 
osteoarthritis of the hand, hip, and knee. Arthritis Care Res (Hoboken). 2012; 64(4): 465-74.

8. McAlindon TE, Bannuru RR, Sullivan MC, Arden NK, Berenbaum F, Bierma-Zeinstra SM, et al. OARSI guidelines for the non-surgical management of knee osteoarthritis. Osteoarthritis Cartilage. 2014; 22(3): 363-88.

9. Van Manen MD, Nace J, Mont MA. Management of primary knee osteoarthritis and indications for total knee arthroplasty for general practitioners. JAOA. 2012; 112(11): 709-15.

10. Küçükoğlu HS. Osteoartritte kanıtlar 1şığında fizik tedavi uygulamaları ve egzersizin önemi. Turkish Journal of Geriatrics. 2011; 14(Suppl 1): 79-81.

11. Van Manen MD, Nace J, Mont MA. Management of primary knee osteoarthritis and indications for total knee arthroplasty for general practitioners. J Am Osteopath Assoc. 2012; 112 (11): 709-15.

12. Daşkapan A, Anaforoğlu B, Karataş M, Kumru Atalay D. Osteoartritli hastalarda fiziksel aktivite düzeyinin değerlendirilmesi. FTR Bilimleri Dergisi. 2011; 14(3-4): 75-9.

13. Gürkan HS, Kırdı N, Tüzün EH, Atilla B. Diz osteoartritli olgularda denge problemleri, fiziksel fonksiyonellik ve yaşam kalitesinin değerlendirilmesi. Akademik Geriatri. 2010; 2: 94-8.

14. Malhotra R. Mastering orthopedic techniques: total knee arthroplasty. 1st ed. New Delhi: Jaypee Brothers, Medical Publishers; 2010.

15. Kohn MD, Sassoon AA, Fernando ND. Classifications in brief: Kellgren-Lawrence classification of osteoarthritis. Clin Orthop Relat Res. 2016; 474(8): 1886-93.

16. Gift AG. Visual analogue scales: measurement of subjective phenomena. Nursing Research. 1989; 38(5): 286-7.

17. Booth, ML, Ainsworth BE, Pratt M, Ekelund U. International physical activity questionnaire: 12country reliability and validity. Med Sci Sports Exerc. 2003; 35(8): 1381-95.

18. Saglam M, Arikan H, Savci S, Inal-Ince D, BosnakGuclu M, Karabulut E ,et al. International physical activity questionnaire: reliability and validity of the Turkish version. Percept Mot Skills. 2010; 111(1): 278-84.

19. Collins NJ, Misra D, Felson DT, Crossley KM, Roos EM. Measures of knee function: international knee documentation committee (IKDC), Subjective knee evaluation form, knee injury and osteoarthritis outcome score (KOOS), Knee injury and osteoarthritis outcome score physical function short form (KOOS\&PS), Knee outcome survey activities of daily living scale (KOS\&ADL), Lysholm knee scoring scale, Oxford knee score (OKS), Western Ontario and McMaster universities osteoarthritis index (WOMAC), Activity rating scale (ARS), and Tegner activity score (TAS)." Arthritis Care and Res. 2011; 63(Suppl 11): 11-22.

20. Tuğay BU, Tuğay N, Güney H, Kınıklı Gİ, Yüksel İ, Atilla B. Oxford knee score: cross-cultural adaptation and validation of the Turkish version in patients with osteoarthritis of the knee. Acta Orthop Traumatol Turc. 2016; 50(2): 198-206.
21. Faucher M, Poiraudeau S, Lefevre-Colau MM Rannou F, Fermanian J, Revel M. Algo-functional assessment of knee osteoarthritis: Comparison of the test-retest reliability and construct validity of the WOMAC and Lequesne indexes. Osteoarthritis and Cartilage. 2002; 10(8): 602-10.

22. Tüzün EH, Eker L, Aytar A, Daşkapan A, Bayramoğlu M. Acceptability, reliability, validity and responsiveness of the Turkish version of WOMAC osteoarthritis index. Osteoarthritis Cartilage. 2005; 13(1): 28-33.

23. Finucane MM, Stevens GA, Cowan MJ, Danaei G, Lin JK, Paciorek CJ, et al. National, regional, and global trends in body-mass index since 1980: systematic analysis of health examination surveys and epidemiological studies with 960 country-years and 9.1 million participants. Lancet. 2011; 377(9765): 557-67.

24. Anderson JJ, Felson DT. Factors associated with osteoarthritis of the knee in the first national health and nutrition examination survey (HANES I): evidence for an association with overweight, race, and physical demands of work. Am J Epidemiol. 1988; 128(1): 179-89.

25. Sridhar MS, Jarrett CD, Xerogeanes JW, Labib SA. Obesity and symptomatic osteoarthritis of the knee. J Bone Joint Surg Br. 2012; 94(4): 433-40.

26. Magliano M. Obesity and arthritis. Menopause Int. 2008; 14(4): 149-54.

27. Sadeghi A, Rad ZA, Sajedi B, Heydari AH, Akbarieh S, Jafari B. Effect of weight losing on the clinical status improvement of patients with knee osteoarthritis. Reumatol Clin. 2019; 15(2): 73-6.

28. Nazari A, Moezy A, Nejati P, Mazaherinezhad A. Efficacy of high-intensity laser therapy in comparison with conventional physiotherapy and exercise therapy on pain and function of patients with knee osteoarthritis: a randomized controlled trial with 12week follow up. Lasers Med Sci. 2019; 34(3): 505-16.

29. Itoh K, Hirota S, Katsumi Y, Ochi H, Kitakoji H. A pilot study on using acupuncture and transcutaneous electrical nerve stimulation (TENS) to treat knee osteoarthritis (OA). Chin Med. 2008; 3: 2.

30. Cherian JJ, Jauregui JJ, Leichliter AK, Elmallah RK, Bhave A, Mont MA.The effects of various physical non-operative modalities on the pain in osteoarthritis of the knee. Bone Joint J. 2016; 98-B(1 Suppl A): 8994.

31. O’Neill TW, Felson DT. Mechanisms of osteoarthritis (OA) pain. Curr Osteoporos Rep. 2018; 16(5): 611-6.

32. Miller RE, Miller RJ, Malfait AM. Osteoarthritis joint pain: the cytokine connection. Cytokine. 2014; 70(2): 185-93.

33. Bindawas SM, Vennu V. Longitudinal effects of physical inactivity and obesity on gait speed in older adults with frequent knee pain: data from the Osteoarthritis Initiative. Int $\mathrm{J}$ Environ Res Public Health. 2015; 12(2): 1849-63.

34. Hinman RS, Bennell KL, Metcalf BR, Crossley KM. Balance impairments in individuals with symptomatic knee osteoarthritis: a comparison with matched controls using clinical tests. Rheumatology (Oxford). 2002; 41(12): 1388-94. 
35. Wallace IJ, Bendele AM, Riew G, Frank EH, Hung HH, Holowka NB, et al. Physical inactivity and knee osteoarthritis in guinea pigs. Osteoarthritis Cartilage. 2019; 27(11): 1721-8.

36. Soutakbar H, Sarah E Lamb, Alan J Silman. The different influence of high levels of physical activity on the incidence of knee OA in overweight and obese men and women-a gender specific analysis. Osteoarthritis Cartilage. 2019; 27(10): 1430-6.

37. Hawke LJ, Shields N, Dowsey MM, Choong PFM, Taylor NF. Physical activity levels after hip and knee joint replacement surgery: an observational study. Clin Rheumatol. 2019; 38(3): 665-74.

38. Peter WF, Tilbury C, Verdegaal SH, Onstenk R, Vehmeijer S, Vermeulenet E, et al. The provision of preoperative and postoperative physical therapy in elderly people with hip and knee osteoarthritis undergoing primary joint replacement surgery. Curr Orthop Prac. 2016; 27(2): 173-83.

39. McCarthy C, Mills P, Pullen R, Roberts C, Silman A, Oldham J. Supplementing a home exercise programme with a classbased exercise programme is more effective than home exercise alone in the treatment of knee osteoarthritis. Rheumatology. 2004; 43(7): 880-6.

40. Su X, Li C, Liao W, Liu J, Zhang H, Li J, Li Z. Comparison of arthroscopic and conservative treatments for knee osteoarthritis: a 5-year retrospective comparative study. Arthroscopy. 2018; 34(3): 652-9.

41. Skou ST, Roos EM, Laursen MB, Rathleff MS, Arendt-Nielsen L, Rasmussen S, et al. Total knee replacement and non-surgical treatment of knee osteoarthritis: 2-year outcome from two parallel randomized controlled trials. Osteoarthritis Cartilage. 2018; 26(9): 1170-80. 